\title{
Screening for depression in older medical inpatients
}

\author{
Sarah Cullum ${ }^{1}$, Sue Tucker ${ }^{2},{\text { Chris } \text { Todd }^{3} \text { and Carol Brayne }}^{4}$ \\ ${ }^{1}$ Academic Unit of Psychiatry, University of Bristol, Bristol, UK \\ ${ }^{2}$ Personal Social Services Research Unit, University of Manchester, Manchester, UK \\ ${ }^{3}$ School of Nursing, Midwifery and Social Work, University of Manchester, Manchester, UK \\ ${ }^{4}$ Department of Public Health and Primary Care, University of Cambridge, Cambridge, UK
}

\section{SUMMARY}

Background Older people with depression make greater use of healthcare services, but the detection of the disorder is poor. The National Service Framework for Older People recommended screening for depression in acute healthcare settings to improve health outcomes of older people. Previous studies, mainly outside the UK, report widely differing rates for depression that do not usefully inform UK practice. Thus the aim of this study is to estimate, in a large representative sample of older medical inpatients in a UK hospital setting, the prevalence of depressive symptoms and ICD-10 depressive disorder and to examine the sensitivity and specificity of the 15-item Geriatric Depression Scale (GDS-15) as a screening instrument. Methods A two-phase prevalence study of depressive disorder was carried out in acute wards of a district general hospital. Six hundred and eighteen $(61 \%)$ of 1009 eligible older medical inpatients were screened using the GDS-15. A stratified sample $(n=223)$ was further assessed using the Geriatric Mental State, from which ICD-10 diagnoses were determined. Results The weighted prevalence estimate of ICD-10 depressive disorder was 17.7\% (95\%CI: 12.9-22.5). Forty-four percent of participants scored above the normally recommended cut-point of $\geq 5$ on the GDS-15. However, on the basis of ROC, the optimal cut-point of the GDS-15 for screening for depressive disorder in this hospitalised population is two points higher at $\geq 7$ (sensitivity 0.74 , specificity 0.81 ).

Conclusions This study confirms that depression is common amongst older UK medical inpatients with 1 in 6 suffering from clinical depression. The cut-point for GDS-15 for this population is $\geq 7$. Copyright $(\mathcal{C} 2006$ John Wiley \& Sons, Ltd.

KEY WORDS - depression; screening; prevalence; validity; healthcare; aged; inpatient; hospital

\section{INTRODUCTION}

Depression is a common mental health disorder in older people. Prevalence estimates of $5-10 \%$ have been reported in population-based community samples (Copeland et al., 1987; Katona et al., 1997; Copeland et al., 1999). As depression has been found to be more common in people who are high utilisers of health care and in those who have chronic medical disorders (Pearson et al., 1999), the prevalence of depressive disorder amongst older general hospital inpatients is likely to be particularly high. Studies car-

*Correspondence to: S. Cullum, Academic Unit of Psychiatry, University of Bristol, Cotham House, Cotham Hill, Bristol, BS6 6JL, UK. Tel: 01454 868327. Fax: 01454 868337. E-mail: sarah.cullum@awp.nhs.uk

Contract/grant sponsor: MRC Health Services Research Training Fellowship; contract/grant number: G106/950.

Contract/grant sponsor: NHS Executive Eastern Research and Development Project Grant; contract/grant number: RCC33041. ried out in North America, Europe and Australasia have reported rates of major depressive disorder in older people hospitalised with medical illness of up to ten times that reported in community samples (Koenig and Blazer, 1992).

In the UK, the National Service Framework (NSF) for Older People (Department of Health, 2001) prioritised the detection and treatment of depression in older people. The introduction of screening of highrisk groups was recommended in the NSF and in recent UK depression guidelines (National Institute for Clinical Excellence, 2004). However, the cost implications for such a programme, particularly in terms of staffing, are potentially enormous. Studies in Europe and North America which used recognised screening tools and standardised diagnostic interviews in older medical inpatients reported between $9 \%$ and $42 \%$ of inpatients scored above recommended screening cut-points (Magni et al., 1985; Koenig et al., 1988a; Koenig et al., 1989; O'Riordan et al., 
1989; Kok et al., 1995; Koenig et al., 1997; Inouye et al., 1998; Covinsky et al., 1999; Linka et al., 2000; Pouget et al., 2000), and between 6\% and $36 \%$ had clinical depressive disorder (Koenig et al., 1988a; Rapp et al., 1988; O'Riordan et al., 1989; Koenig et al., 1991; Burn et al., 1993; Hammond et al., 1993; Fenton et al., 1994; Kok et al., 1995; Koenig et al., 1997; Linka et al., 2000; Schneider et al., 2000; Borin et al., 2001). This considerable variation is likely to be accounted for by differences in definition of screening, instruments used, variations in the target populations, approaches to sampling and accuracy of estimates.

Two UK-based studies (Burn et al., 1993; Hammond et al., 1993) reported similar prevalence rates for depressive disorder (23\% and $28 \%$ respectively) but these were carried out over ten years ago since when admission policies may have changed. Decision makers considering the implications of introducing depression screening policies in the UK thus need contemporary empirical data regarding the probable numbers of older general hospital inpatients in the UK that would screen positive for depression and the proportion that would have true depressive disorder.

The aim of this paper is to contribute to the UK evidence base by reporting the prevalence of depressive symptoms and depressive disorder in a large representative population sample of older medical inpatients in a UK district general hospital setting. Its specific objectives are to:

1. Report the proportion of the sample scoring above various cut-points on the 15-item Geriatric Depression Scale (GDS-15).

2. Report the prevalence of ICD-10 depressive disorder.

3. Examine the sensitivity and specificity of the GDS-15 as a screening instrument for ICD-10 depressive disorder in this population.

\section{METHODS}

This prevalence study formed part of a larger ongoing randomised controlled trial of liaison psychiatry in older medical inpatients in a district general hospital (DGH) in rural East Anglia.

\section{Sample}

Over a period of 15 months all consecutive acute medical admissions to the DGH were monitored to ascertain those eligible for the prevalence study. The eligibility criteria were age 65 and over, current residence within the area covered by the West Suffolk Primary Care Trust and to have been in hospital for between 3 and 6 days at the time of screening. A 50\% random sample of patients was constructed from the eligible patients. Patients were assessed and excluded if they had severe dysphasia, severe deafness or were too physically unwell or confused to participate. Participants with a current diagnosis of alcohol dependency were also excluded as they may have had depressive symptoms secondary to alcohol dependency, leading to overestimation of the prevalence of depression. The remainder were asked for consent to a screening interview and potential participation in the on-going randomised controlled trial of liaison psychiatry. The study received ethical approval from the West Suffolk Hospital LREC.

\section{Measures}

Screening interview. The first author (SC) screened participants for depression using the GDS-15 (Sheikh and Yesavage, 1986), and for cognitive impairment using the 10-item Abbreviated Mental Test Score (AMTS) (Hodkinson, 1972).

A higher score on the GDS-15 indicates that the patient has more depressive symptoms. A score of 6 or 7 on the AMTS indicates mildly impaired cognitive function, and a score lower than 6 indicates more severe cognitive impairment. Participants with an AMTS score $<6$ were excluded as the GDS-15 is not valid in patients with more severe cognitive impairment or dementia (Burke et al., 1989).

Assessment interview. The screened sample was stratified by GDS-15 score: all participants who scored $\geq 8$ on the GDS- 15 and a random $25 \%$ sample of those who scored $<8$ were requested to take part in a further assessment interview with an independent research assistant. The anxiety and depression items of the Geriatric Mental State (GMS) (Copeland et al., 1976) were included in the second interview. Sensitive questions in the GMS schedule (e.g. questions about suicidal ideas) were difficult to administer on an open ward and were omitted. These omissions did not affect the threshold for being diagnosed with ICD-10 depressive disorder, but did affect the severity rating for the disorder if diagnosed. For this reason severity ratings were not reported in this study. 


\section{Statistical methods}

The data from the assessment interview were entered into a GMS-ICD-10 mood algorithm (available from the authors of the GMS, but not currently in the public domain), which generates an ICD-10 diagnosis of depressive disorder.

Due to the stratified design of the study an inverse probability weighted analysis was carried out in order to calculate the prevalence of depressive disorder in

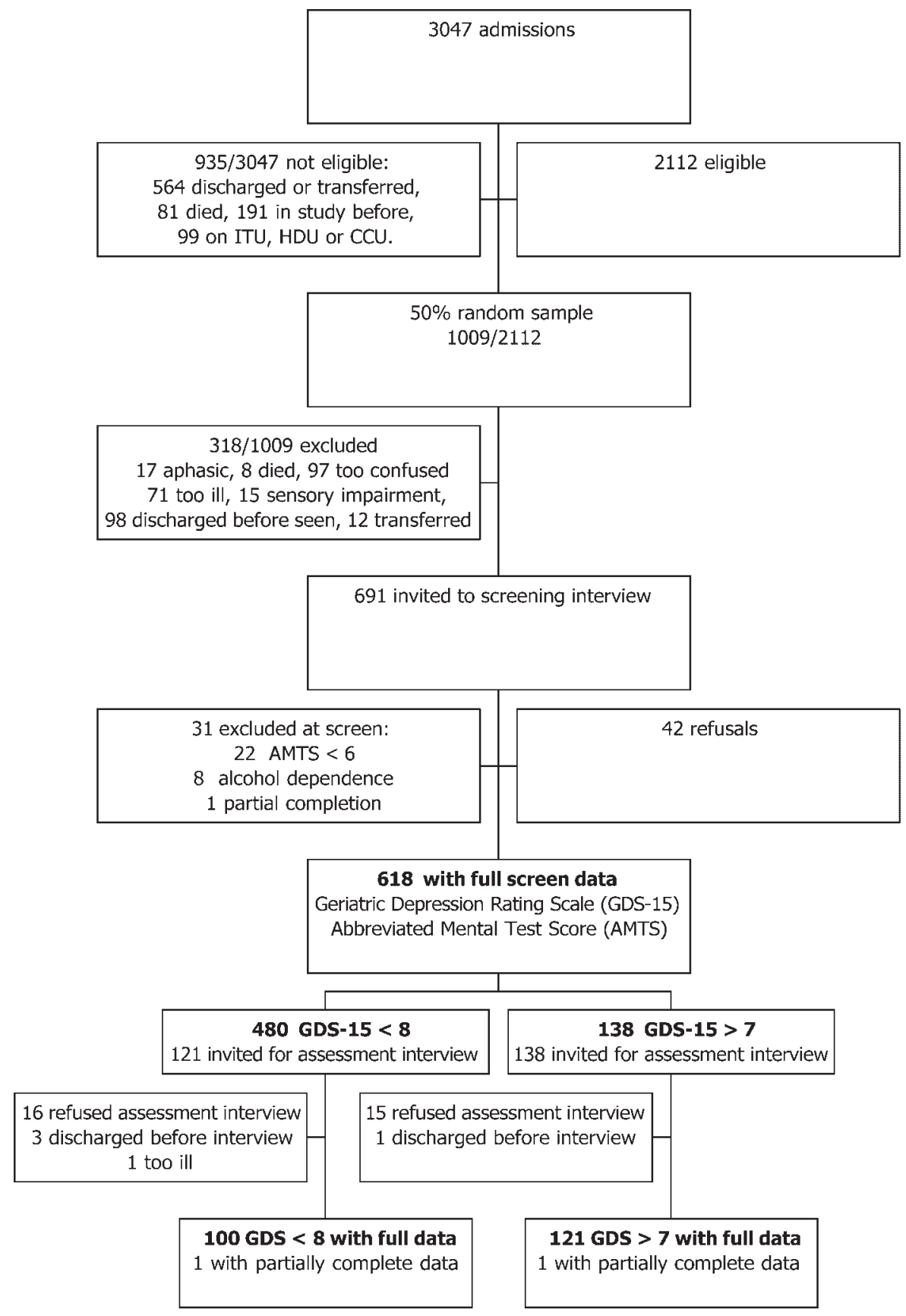

Figure 1. Patient flow diagram 
Table 1. Characteristics of refusers and completers at screening interview and assessment interview

\begin{tabular}{|c|c|c|c|c|c|c|}
\hline & $\begin{array}{l}\text { Completed } \\
\text { screen } \\
\text { interview } \\
(n=618)\end{array}$ & $\begin{array}{l}\text { Eligible but } \\
\text { refused } \\
\text { screen } \\
(n=42)\end{array}$ & $\begin{array}{l}\text { Statistical } \\
\text { test and } \\
p \text {-value }\end{array}$ & $\begin{array}{l}\text { Complete } \\
\text { assessment } \\
\text { interview } \\
(n=221)\end{array}$ & $\begin{array}{c}\text { Refused/partially } \\
\text { completed } \\
\text { assessment } \\
\text { interview }(n=38)\end{array}$ & $\begin{array}{l}\text { Statistical } \\
\text { test and } \\
p \text {-value }\end{array}$ \\
\hline Mean age in years (SD) & $80.2(7.48)$ & $81.5(7.26)$ & $t$-test: 0.28 & $80.3(7.49)$ & $81.0(7.84)$ & $t$-test; $p=0.59$ \\
\hline$\%$ women & 59 & 76 & $\chi^{2}: 0.01$ & 60 & 66 & $\chi^{2} ; p=0.51$ \\
\hline$\%$ AMTS score $<8$ & 15 & $\begin{array}{l}\text { Data not } \\
\text { collected }\end{array}$ & No test & 17 & 26 & $\begin{array}{l}\text { Fisher's exact; } \\
p=0.17\end{array}$ \\
\hline$\%$ GDS-15 score $\geq 8$ & 22 & $\begin{array}{l}\text { Data not } \\
\text { collected }\end{array}$ & No test & 45 & 48 & $\begin{array}{l}\text { Fisher's exact; } \\
p=0.29\end{array}$ \\
\hline
\end{tabular}

the eligible population (Pickles et al., 1995). The same weighting method was used to assess the validity of the 15 -item GDS scale.

Statistical analyses were carried out using Intercooled STATA version 8.0.

\section{RESULTS}

Figure 1 presents the flow of patients into the study; 2112 of the 3047 admissions considered for the study met the eligibility criteria and 691 of the 1009 potential participants selected into the random sample met the inclusion criteria for the screening interview. Six hundred and eighteen of these had complete screen data for analysis.

\section{Sample characteristics}

There was no difference in age between participants who completed the screening interview and those

Table 2. Proportion of participants scoring at each GDS-15 cut-point

\begin{tabular}{lc}
\hline GDS-15 cut-point & $\begin{array}{c}\text { Proportion of participants scoring } \\
\text { above cut-point }(95 \% \mathrm{CI})\end{array}$ \\
\hline$\geq 1$ & $0.95(0.93,0.96)$ \\
$\geq 2$ & $0.84(0.81,0.87)$ \\
$\geq 3$ & $0.71(0.67,0.74)$ \\
$\geq 4$ & $0.57(0.53,0.61)$ \\
$\geq 5$ & $0.44(0.40,0.48)$ \\
$\geq 6$ & $0.34(0.31,0.38)$ \\
$\geq 7$ & $0.28(0.25,0.32)$ \\
$\geq 8$ & $0.22(0.19,0.26)$ \\
$\geq 9$ & $0.15(0.13,0.18)$ \\
$\geq 10$ & $0.11(0.09,0.14)$ \\
$\geq 11$ & $0.08(0.06,0.10)$ \\
$\geq 12$ & $0.06(0.04,0.07)$ \\
$\geq 13$ & $0.03(0.02,0.05)$ \\
$\geq 14$ & $0.01(0.00,0.02)$ \\
15 & $0.00(0.00,0.01)$ \\
\hline
\end{tabular}

Copyright (C) 2006 John Wiley \& Sons, Ltd. who refused the interview, but a higher proportion of refusers were women (Table 1).

Four hundred and eighty of the screened sample scored $<8$ and 138 scored $\geq 8$ on the GDS-15. Of the 138 screen positives and 121 (25\% random sample) screen negatives invited for assessment interview, 36 did not receive the interview (see Figure 1 for reasons) and two participants abandoned the assessment interview before the diagnostic interview was completed. There were no differences between participants who accepted the assessment interview and those that refused in terms of their age, sex, AMTS score and GDS score (Table 1).

\section{Proportion of participants scoring above GDS-15 cut-points}

The proportions of participants scoring above each cut-point on the GDS-15 scale are shown in Table 2.

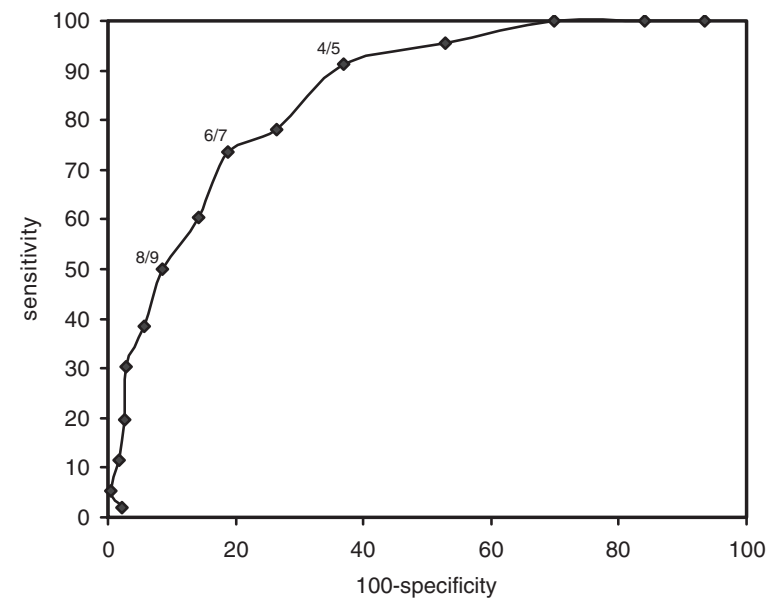

Figure 2. Receiver operating characteristic curve for GDS-15 in older medical inpatients 


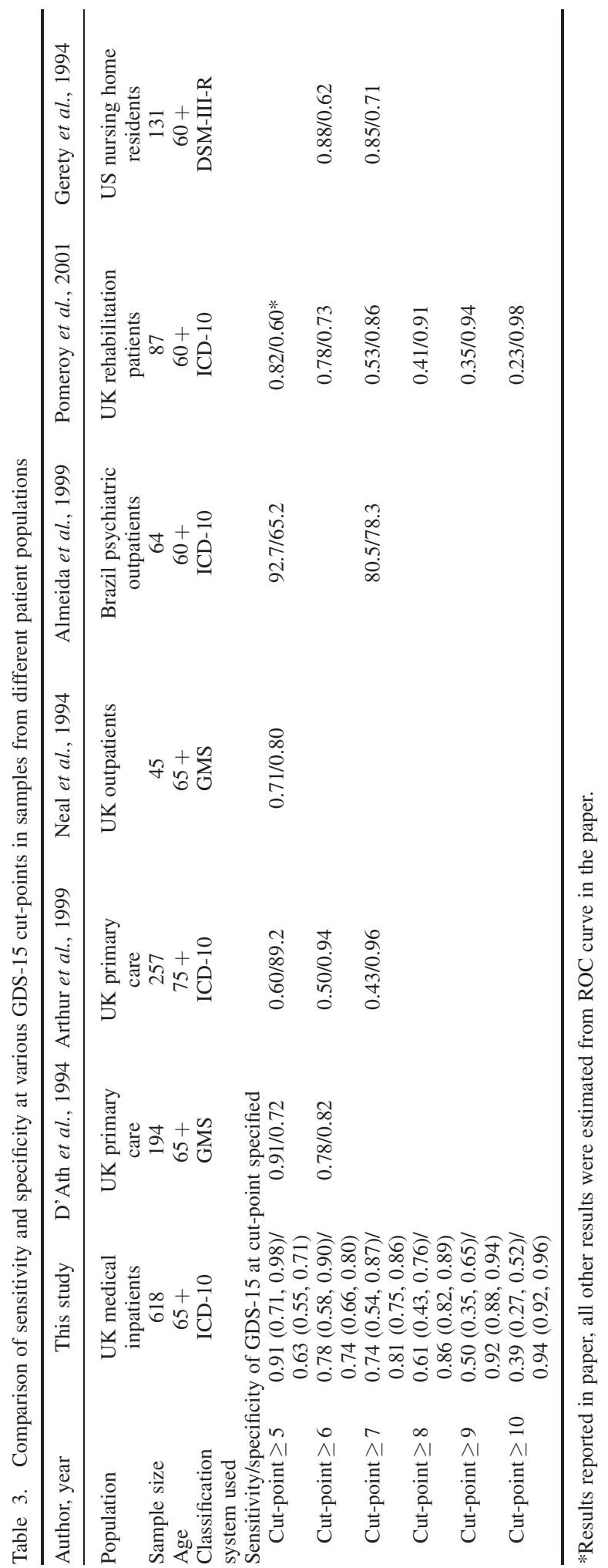




\section{Prevalence of ICD-10 depressive disorder}

Using the GMS-ICD-10 mood algorithm, the weighted prevalence estimate of ICD-10 depressive disorder in the population from which this sample was drawn was $17.7 \%$ [95\% Confidence Intervals (CI) 12.9-22.5].

\section{Sensitivity and specificity of GDS-15}

The Receiver Operating Characteristic (ROC) curve is shown in Figure 2, and Table 3 shows the weighted sensitivity and specificity of the GDS-15 at cut-points 5 to 10 .

\section{DISCUSSION}

\section{Summary of findings}

The main findings of this study were that a considerable proportion of older medical inpatients scored above the recommended cut-point on a widely used depression screening tool, the GDS-15. Forty-four percent of study participants scored above the generally recommended cut-point of $\geq 5$ on the GDS-15, $34 \%$ scored $\geq 6$ and $28 \%$ scored $\geq 7$. The prevalence of ICD-10 depressive disorder was $17.7 \%$. The ROC curve shows that the GDS-15 cut-point $\geq 7$ was the optimal cut-point for screening for depression in this population, which is two points higher than the cut-point of $\geq 5$ recommended for community-based populations. At cut-point $\geq 7$ the sensitivity was 73.7 and the specificity was 81.2.

\section{Strengths and weaknesses}

The main strength of the study was that that the sample size is larger than all except one previous study that evaluated GDS-30 (Koenig et al., 1989), allowing a more accurate estimation of prevalence in the target population. Another strength was the design-based analysis that adjusted for the sampling design and missing data, permitting accurate evaluation of the validity of the 15-item GDS in the general hospital population.

The main weakness was that the findings could only be generalised to the $40 \%$ of patients that met the eligibility and inclusion criteria. Patients who were discharged early or were too ill/confused to participate in the study might have had different characteristics to those who took part. But the findings are generalisable to those older medical inpatients who are most likely to be screened in a 'real world' NHS setting, i.e. those who stay in hospital for more than 3 days and are fit enough to complete a screening questionnaire. It should also be noted that, although questions about suicidality were excluded in this study, this would not be acceptable in clinical practice as the elderly physically ill have one of the highest rates of completed suicide.

\section{Comparison with previous studies}

Depressive symptoms. More participants scored above the recommended GDS-15 cut-points than in three similar studies in which $34 \%$ (Covinsky et al., 1999) and 22\% (Pouget et al., 2000) scored $\geq 6$; and $18 \%$ scored $\geq 7$ (Inouye et al., 1998). The difference in findings may reflect the fact that the other populations sampled were non-UK based and aged over 70. The salient point is that between one-fifth and one-third of older medical inpatients score above the recognised screening cut-point of 5 on the GDS15 and approximately half of these will have true depressive disorder.

Depressive disorder. The prevalence of depressive disorder lay in the middle of the range found in previous studies $(6 \%-36 \%)$. The prevalence of depressive disorder is dependent upon the classification system used for diagnosis. For example, the prevalence of DSM-III depressive disorder tends to be lower than ICD-10 depressive disorder as DSM criteria require an additional depressive symptom to be endorsed compared to ICD-10. Only one of the studies in the literature review used the ICD-10 classification system and reported a prevalence of $35.5 \%$ for major depressive disorder, but after differentiating for the aetiology of symptoms, this estimate dropped to $14.1 \%$ (Schneider et al., 2000). This figure is similar to our finding of $17.7 \%$ for ICD-10 depressive disorder derived from the GMS, which similarly instructs interviewers to score only depressive symptoms that are clearly not due to physical illness.

Instrument performance. The study confirms the validity of the GDS-15 in diagnosing ICD-10 depressive disorder in older medical inpatients. The findings replicate those of several studies (D'Ath et al., 1994; Gerety et al., 1994; Neal and Baldwin, 1994; Almeida et al., 1999; Arthur et al., 1999; Pomeroy et al., 2001) that tested the validity of the GDS-15 in patients over the age of 60 (Table 3). In particular, the findings confirm that, in secondary care populations, the optimal GDS-15 cut-point tends to be $1-2$ points higher 
than that recommended for populations with better physical health.

\section{Implications for clinical practice}

Staff in general hospitals detect only $10-30 \%$ of elderly patients with depression (Koenig, 1988b; Rapp et al., 1988; Jackson and Baldwin, 1993), yet depression has a greater impact on health-related quality of life than do many chronic medical disorders (Wells et al., 1989; Hays et al., 1995), and is associated with higher mortality, increased duration of stay in hospital, higher risk of re-hospitalisation and greater resource use (Koenig and Kuchibhatla, 1998; Koenig et al., 1999a; Koenig et al., 1999b; Herrman et al., 2002). The effective identification and treatment of depression in this patient group may therefore not only improve the mental health outcomes and quality of life of people already multiply disadvantaged in their physical and functional status, but also reduce their length of hospital stay and subsequent use of healthcare services.

This study confirms that depression is common in older inpatients and that the GDS-15 is a useful screening tool. The cut-point used for screening should, however, be considered carefully: a lower cut-point may result in a high number of false positives that could prove costly to the NHS if every patient required further specialist assessment. This is particularly relevant if shorter versions of the GDS are recommended for screening, e.g. in the guidance on assessment scales for the Single Assessment Process (Department of Health, 2002). A higher cutpoint will result in decreased sensitivity but may be a more cost-effective option in clinical practice (Cullum et al., 2003). However, the cost-effectiveness of screening for depression will ultimately depend upon additional evidence that treatment of the disorder leads to better outcomes and/or reduced costs.

\section{CONCLUSIONS}

Depressive symptoms and depressive disorder are common amongst older UK medical inpatients, but screening at previously recommended cut-points may generate high numbers of false positives with implications for the cost-effectiveness of subsequent assessments. On the basis of the ROC curve in this study we recommend a cut-point of GDS- 15 cut-point of $\geq 7$ for elderly medical inpatients. Further research is required to evaluate the effectiveness and costeffectiveness of the treatment of depression in this population.

\section{KEY POINTS}

- Depression is common in older people with physical health problems, but is often undetected and untreated. This may be partly due to the overlap of somatic symptoms.

- This study shows that $44 \%$ of older medical inpatients score above the normally recommended cut-point for depression $(\geq 5)$ on the 15-item Geriatric Depression Scale, and that the prevalence of ICD-10 depressive disorder is $17.7 \%$ (95\% CI: 12.9-22.5).

- The optimal cut-point for GDS-15 in this hospitalised population is $\geq 7$, which is two points higher than the recommended cut-point for older people living in the community. Healthcare services planning to introduce depression screening should consider the cost-effectiveness of the cut-point used.

\section{ACKNOWLEDGEMENTS}

The authors would like to thank, Maggie Bray, Barbara Lee and Lu Gao. This work was supported by a MRC Health Services Research Training Fellowship (G106/950) and a NHS Executive Eastern Research and Development Project Grant (RCC33041).

\section{REFERENCES}

Almeida OP, Almeida SA. 1999. Short versions of the geriatric depression scale: a study of their validity for the diagnosis of a major depressive episode according to ICD-10 and DSM-IV. Int J Geriatr Psychiatry 14: 858-865.

Arthur A, Jagger C, Lindesay J, Graham C, Clarke M. 1999. Using an annual over-75 health check to screen for depression: validation of the short Geriatric Depression Scale (GDS15) within general practice. Int J Geriatr Psychiatry 14: 431-439.

Borin L, Menon K, Raskin A, Ruskin P. 2001. Predictors of depression in geriatric medically ill inpatients. Int $J$ Psychiatry Med 31: 1-8.

Burke WJ, Houston MJ, Boust SJ, Roccaforte WH. 1989. Use of the Geriatric Depression Scale in dementia of the Alzheimer type. J Am Geriatr Soc 37: 856-860.

Burn W, Davies K, McKenzie F, Brothwell J. 1993. The prevalence of psychiatric illness in acute geriatric admissions. Int J Geriatr Psychiatry 8: 171-174.

Copeland JR, Beekman AT, Dewey ME, et al. 1999. Depression in Europe. Geographical distribution among older people. $\mathrm{Br}$ J Psychiatry 174: 312-321.

Copeland JR, Kellerher M, Kellet J, Gourlay A. 1976. A semistructured clinical interview for the assessment and diagnosis of mental state in the elderly: the geriatric mental state schedule. Psychol Med 6: 439-449.

Copeland J, Dewey M, Wood N, Searle R, Davidson I, McWilliam C. 1987. Range of mental illness among the elderly in the 
community. Prevalence in Liverpool using the GMS-AGECAT package. Br J Psychiatry 150: 817-824.

Covinsky KE, Kahana E, Chin MH, Palmer RM, Fortinsky RH, Landefeld CS. 1999. Depressive symptoms and 3-year mortality in older hospitalized medical patients. Ann Intern Med 130: 563569.

Cullum S, Nandhra H, Darley J, Todd C. 2003. Screening for depression in older people on medical wards: which cut-point should we use? Int J Geriatr Psychiatry 18: 358-359.

D’Ath P, Katona P, Mullan E, Evans S, Katona C. 1994. Screening, detection and management of depression in elderly primary care attenders. I: the acceptability and performance of the 15 item Geriatric Depression Scale (GDS15) and the development of short versions. Fam Pract 11: 260-266.

Department of Health. 2001. National Service Framework for Older People. Department of Health: London.

Department of Health. 2002. Guidance on the single assessment process for older people. Department of Health HSC 2002/001; LAC(2002) 1.

Fenton FR, Cole MG, Engelsmann F, Mansouri I. 1994. Depression in older medical inpatients. Int J Geriatr Psychiatry 9: 279-284.

Gerety MB, Williams JW, Mulrow CD, et al. 1994. Performance of case-finding tools for depression in the nursing home: influence of clinical and functional characteristics and selection of optimal threshold scores. J Am Geriatr Soc 42: 1103-1109.

Hammond MF, Evans ME, Lye M. 1993. Depression in medical wards [1]. Int J Geriatr Psychiatry 8: 957.

Hays RD, Wells KB, Sherbourne CD, Rogers W, Spritzer K. 1995. Functioning and well-being outcomes of patients with depression compared with chronic general medical illnesses. Arch Gen Psychiatry 52: 11-19.

Herrman H, Patrick DL, Diehr P, et al. 2002. Longitudinal investigation of depression outcomes in primary care in six countries: the LIDO study: functional status, health service use and treatment of people with depressive symptoms. Psychol Med 32: 889-902.

Hodkinson M. 1972. Evaluation of a mental test score for assessment of mental impairment in the elderly. Age Ageing 1: 233 238.

Inouye SK, Peduzzi PN, Robison JT, Hughes JS, Horwitz RI, Concato J. 1998. Importance of functional measures in predicting mortality among older hospitalized patients. JAMA 279: 1187-1193.

Jackson R, Baldwin B. 1993. Detecting depression in elderly medically ill patients: the use of the Geriatric Depression Scale compared with medical and nursing observations. Age Ageing 22 : 349-353.

Katona CL, Manela M, Livingston G. 1997. Comorbidity with depression in older people: the Islington study. Aging Ment Health 1: 57-61.

Koenig HG, Blazer DG. 1992. Epidemiology of geriatric affective disorders. Clin Geriatr Med 8: 235-251.

Koenig HG, Meador KG, Cohen HJ, Blazer DG. 1988a. Depression in elderly hospitalized patients with medical illness. Arch Intern Med 148: 1929-1936.

Koenig HG, Meador KG, Cohen HJ, Blazer DG. 1988b. Self-rated depression scales and screening for major depression in the older hospitalized patient with medical illness. J Am Geriatr Soc 36: 699-706.

Koenig HG, Meador KG, Shelp F, Goli V, Cohen HJ, Blazer DG. 1991. Major depressive disorder in hospitalized medically ill patients: an examination of young and elderly male veterans. J Am Geriatr Soc 39: 881-890.

Koenig HG, Shelp F, Goli V, Cohen HJ, Blazer DG. 1989. Survival and health care utilization in elderly medical inpatients with major depression. J Am Geriatr Soc 37: 599-606.

Koenig HG, George LK, Larson DB, McCullough ME, Branch PS, Kuchibhatla M. 1999a. Depressive symptoms and nine-year survival of 1,001 male veterans hospitalized with medical illness. Am J Geriatr Psychiatry 7: 124-131.

Koenig HG, George LK, Peterson BL, Pieper CF. 1997. Depression in medically ill hospitalized older adults: prevalence, characteristics, and course of symptoms according to six diagnostic schemes. Am J Psychiatry 154: 1376-1383.

Koenig HG, Kuchibhatla M. 1999b. Use of health services by medically ill depressed elderly patients after hospital discharge. Am J Geriatr Psychiatry 7: 48-56.

Koenig H, Kuchibhatla M. 1998. Use of health services by hospitalized medically ill depressed elderly patients. Am J Psychiatry 155: 859-860.

Kok RM, Heeren TJ, Hooijer C, Dinkgreve MA, Rooijmans HG. 1995. The prevalence of depression in elderly medical inpatients. $J$ Affect Disord 33: 77-82.

Linka E, Bartko G, Agardi T, Kemeny K. 2000. Dementia and depression in elderly medical inpatients. Int Psychogeriatr 12: 67-75.

Magni G, De-Leo D, Schifano F. 1985. Depression in geriatric and adult medical inpatients. J Clin Psychol 41: 337-344.

National Institute for Clinical Excellence. 2004. Depression: Management of Depression in Primary and Secondary Care. Clinical Guideline 23. NICE: London.

Neal RM, Baldwin RC. 1994. Screening for anxiety and depression in elderly medical outpatients. Age Ageing 23: 461-464.

O'Riordan TG, Hayes JP, Shelley R, et al. 1989. The prevalence of depression in an acute geriatric medical assessment unit. Int J Geriatr Psychiatry 4: 17-21.

Pearson SD, Katzelnick DJ, Simon GE, Manning WG, Helstad CP, Henk HJ. 1999. Depression among high utilizers of medical care. J Gen Intern Med 14: 461-468.

Pickles A, Dunn G, Vazquez-Barquero JL. 1995. Screening for tratification in two-phase ('two-stage') epidemiological surveys. Stat Methods Med Res 4: 73-89.

Pomeroy IM, Clark CR, Philp I. 2001. The effectiveness of very short scales for depression screening in elderly medical patients. Int J Geriatr Psychiatry 16: 321-326.

Pouget R, Yersin B, Wietlisbach V, Bumand B, Bula CJ. 2000. Depressed mood in a cohort of elderly medical inpatients: prevalence, clinical correlates and recognition rate. Aging (Milano) 12: 301-307.

Rapp SR, Parisi SA, Walsh DA, Wallace CE. 1988. Detecting depression in elderly medical inpatients. J Consult Clin Psychol 56: 509-513.

Schneider G, Kruse A, Nehen HG, Senf W, Heuft G. 2000. The prevalence and differential diagnosis of subclinical depressive syndromes in inpatients 60 years and older. Psychother Psychosom 69: 251-260.

Sheikh J, Yesavage J. 1986. Geriatric Depression Scale (GDS): recent evidence and development of a shorter version. Clin Gerontol 5: 165-173.

Wells KB, Stewart A, Hays RD, et al. 1989. The functioning and well-being of depressed patients. Results from the Medical Outcomes Study. JAMA 262: 914-919. 